\title{
Na-P1 zeolite synthesis and its crystalline structure ripening through hydrothermal process using coal combustion by-products as substrates
}

\author{
Piotr Kunecki ${ }^{1}$, Rafał Panek ${ }^{1}$, Magdalena Wdowin ${ }^{2}$ \\ ${ }^{1}$ Lublin University of Technology, Civil Engineering and Architecture Faculty; ul. Nadbystrzycka 40, 20-618 Lublin, Poland; \\ e-mail:kunecki_piotr@interia.pl \\ ${ }^{2}$ The Mineral and Energy Economy Research Institute of the Polish Academy of Sciences; ul. Wybickiego 7, \\ 31-261 Krakow, Poland
}

(C) 2016 Authors. This is an open access publication, which can be used, distributed and reproduced in any medium according to the Creative Commons CC-BY 4.0 License requiring that the original work has been properly cited.

Energy industry sector is one of the major environment pollutants. This branch also generates significant amounts of by-products such as slugs, slug-ash mixtures, ashes and microspheres, which can be very harmful for the earth ecosystems. Statistically the microspheres (MIC) constitute from $0.6 \%$ to $2.5 \%$ of the total amount of post combustion wastes. MIC occurs mainly in fly ashes (less often in slugs) as the smallest, hollow, spherical particles. MIC is composed mainly of crystalline and amorphous aluminosilicate phases. The combustion conditions have strong influence on MIC composition. Mineral and chemical composition of MIC is very similar to F type of fly ashes; consequently there is a possibility to use them as substrates for zeolite synthesis. Zeolites are minerals from microporous, aluminosilicate group (Szala et al. 2015). Among others, they are characterized by specific channels and chambers occurrence in their structure, which results in a number of important features like: ion exchange, sorption, molecular sieve or catalytic properties. This is the reason for wide use of zeolites in numerous industrial sectors (Ahmaruzzaman 2010). The aim of this study is a synthesis of Na-P1 zeolite at semi-technical scale by conversion of microspheres under hydrothermal conditions in an alkaline medium. This study involves also research of Na-P1 zeolite structure ripening in order to optimize the synthesis conditions. Microspheres from Stalowa
Wola Power Plant (Poland) were used as a substrate. For the synthesis of Na-P1 phase the following conditions were applied: $90 \mathrm{dm}^{3}$ of water, $15 \mathrm{~kg}$ of microsphere, $11 \mathrm{~kg}$ of sodium hydroxide $\left(3 \mathrm{~mol} / \mathrm{dm}^{3}\right)$, temperature: $80^{\circ} \mathrm{C}$, and reaction time up to $26 \mathrm{~h}$ (Franus et al. 2014). The zeolite conversion was performed on semi-technical scale installation (Wdowin et al. 2014). During the conversion, samples were collected from the reactor after $2,4,6,10,14,26$ hours. To investigate the influence of time for zeolitization process efficiency these samples were analyzed in terms of chemical and mineral composition, structural and textural properties. The main attention was paid to the evolution of the Na-P1 unit cell parameters observed as a function of time (calculations and models were performed for every sample).

The phase's composition was determined with powder X-ray diffraction (XRD) method using a PANalytical X'pert MPD diffractometer (with a PW 3050/60 goniometer), Cu lamp, and a graphite monochromator. The analysis was performed within the angle range of 5-65 20. PANalytical X'Pert Highscore software was used to process the diffraction data. The identification of mineral phases was based on the PDF-2 release 2010 database formalized by the ICD and IZA-SC Database of Zeolite Structures. The experimental calculations of the unit cell parameters were performed using UnitCell software. The spatial model of Na-P1 
zeolite cell was prepared using Mercury 3.7 Windows software. The morphological forms and the chemical composition of the main mineral components were determined with scanning electron microscope (SEM) FEI Quanta 250 FEG equipped with the SE detector and a system of chemical composition analysis based on energy dispersive X-ray-EDS of EDAX company. $\mathrm{N}_{2}$ adsorption-desorption measurements were carried out at $77 \mathrm{~K}$ using ASAP 2020 volumetric adsorption analyzer (Micromeritics). The specific surface areas $\left(\mathrm{S}_{\mathrm{BET}}\right)$ of the samples were evaluated using the standard Brunauer-Emmett-Teller (BET) method for nitrogen adsorption data in the range of relative pressure $p / p_{0}$ from 0.06 to 0.3 . The total pore volumes were estimated from single-point adsorption at a relative pressure of 0.98 .

XRD data indicates that main phases in microsphere are amorphous aluminosilicate glass, mullite and quartz. The obtained product is dominated by $\mathrm{Na}-\mathrm{P} 1$ phase. Experimental calculations of cell parameters and fabricated models confirm crystallographic similarity to Na-P1 pattern. Noteworthy is the fact that the unit cell parameters depend on reaction time. Calculations indicate that the cell parameters (walls length: $a, b$, $c$ and cell volume) increase with time towards to pattern values. This phenomenon may be interpreted as a ripening of crystalline structure. An in-depth look at this matter can lead to better estimation of synthesis conditions, which have a significant impact to the total cost of zeolites production - especially at a larger scale. SEM shows progressive dissolution (also as a function of time) of aluminosilicate glass in favor of crystallization of zeolite phase. EDS analysis confirms similarity of chemical composition of the obtained samples to a standard Na-P1 zeolite. Calculated textural properties indicate increase of $\mathrm{S}_{\mathrm{BET}}$ with the reaction time. Simultaneously, the average pore diameters decrease. The $\mathrm{S}_{\mathrm{BET}}$ of synthetized Na-P1 was $4.62 \mathrm{~m}^{2} / \mathrm{g}$ after $2 \mathrm{~h}$ but it increased to $47.92 \mathrm{~m}^{2} / \mathrm{g}$ after $26 \mathrm{~h}$. This is an effect of growing contribution of zeolite phase in relation to the initial substrates in the sample during the reaction time.

The experimental conditions allowed synthesizing Na-P1 zeolite from microsphere particles in the prototype installation. Zeolitization process strongly influences the textural properties by increasing $\mathrm{S}_{\mathrm{BET}}$ and improving pore structure. The microsphere from Stalowa Wola Power Plant is a promising material for the synthesis of $\mathrm{Na}-\mathrm{P} 1$ zeolite in the prototype installation. Still, the reaction parameters should be reconsidered, basing on the obtained results, in order to reduce the cost of the zeolite production as much as possible. This is required before proceeding to the full technical production scale. To observe increase of zeolite amount in entirety synthesis batch (and to link it with cell behavior) the Rietveld analysis will be provided.

This work was financed by the National Centre for Research and Development project Lider contract number LIDER/384/L-6/14/NCBR/2015.

\section{REFERENCES}

Ahmaruzzaman M., 2010. A review on the utilization of fly ash. Progress in Energy and Combustion Science, 36, 327-363.

Franus W., Wdowin M. \& Franus M., 2014. Synthesis and characterization of zeolites prepared from industrial fly ash. Environmental Monitoring and Assessment, 186, 5721-5729.

Szala B., Bajda T., Matusik J., Zięba K. \& Kijak B., 2015. BTX sorption on Na-P1 organo-zeolite as a process controlled by the amount of adsorbed HTMA. Microporous and Mesoporous Materials, 202, 115-123.

Wdowin M., Franus M., Panek R., Bandura L. \& Franus W., 2014. The conversion technology of fly ash into zeolites. Clean Technology and Environmental Policy, 16, 1217-1223. 